\title{
Conditional Intravesical Recurrence-free Survival Rate after Radical Nephroureterectomy with Bladder Cuff Excision for Upper Urothelial Carcinoma
}

\author{
Jae Hoon Chung \\ Samsung Medical Center \\ Wan Song \\ Samsung Medical Center \\ Minyong Kang \\ Samsung Medical Center \\ Hwang Gyun Jeon \\ Samsung Medical Center \\ Byong Chang Jeong \\ Samsung Medical Center \\ Seong IL Seo \\ Samsung Medical Center

\section{Seong Soo Jeon} \\ Samsung Medical Center \\ Hyun Moo Lee \\ Samsung Medical Center \\ Hyun Hwan Sung ( $\square$ hhsunguro@gmail.com ) \\ Samsung Medical Center
}

\section{Research Article}

Keywords: Nephroureterectomy, recurrence, urinary bladder

Posted Date: December 31st, 2020

DOI: https://doi.org/10.21203/rs.3.rs-136383/v1

License: @ (1) This work is licensed under a Creative Commons Attribution 4.0 International License. Read Full License 


\section{Abstract}

To evaluate the incidence and risk factors of (intravesical recurrence) IVR by analyzing a relatively large number of patients who underwent radical nephroureterectomy with bladder cuff excision (RNUx) for upper urothelial carcinoma (UTUC). Additionally, conditional IVR-free survival in patients with UTUC who had no history of bladder cancer and no concomitant bladder cancer was evaluated. We retrospectively analyzed the data of 1,095 patients with UTUC who underwent RNUx. The baseline characteristics, bladder tumor history, and UTUC characteristics were analyzed to evaluate oncological outcomes. To determine the factors affecting IVR, surgical modality, use of preoperative ureteroscopic examination (URS), TNM stage, and pathological outcomes were evaluated. Multivariable Cox regression analyses were performed to evaluate factors affecting IVR, and conditional IVR-free survival rate was analyzed using Kaplan-Meier curves. Among the 1,095 patients, 462 patients developed IVR and mean time of IVR was $13.08 \pm 0.84$ months after RNUx. A total of $30.74 \%$ of the IVR group and $15.32 \%$ of the without IVR group had a past history of bladder cancer ( $p<$ 0.001). In the multivariable analysis, a previous history of bladder cancer, multifocal tumors, the use of preoperative URS, the extravesical bladder cuffing method, lymph node involvement, positive surgical margins, and the use of adjuvant chemotherapy were determined to affect the IVR. The conditional IVRF rate at 12 months after RNUx was $74.0 \%$, for those who IVRF for 12 months, the IVRF rate was $87.1 \%$ for the next 12 months ( 24 months after RNUx), and for the patients who IVRF for 24 months, the IVRF rate was 93.6\% for the next 12 months (36 months after RNUx) and the IVRF rate was $97.3 \%$ for the next 12 months in IVRF of 60 months patients. The mean IVRF survival period of all patients was 136.84 months, 156.24 months in the patients with 6 months IVRF, 175.38 months for the patients with 12 months IVRF, 189.14 months for the patients with 36 months IVRF, and mean IVRF survival period was 178.21 months in 60 months IVRF patients. In 24 months IVRF patients after RNUx, only URS was evaluated to independently affect IVR (HR 1.945, $p=0.040)$. In patients with 36 months or more IVRF, there was no significant factor affecting IVR. Active IVR assessment is required until 36 months after RNUx. In addition, patient education and regular screening test such as urine analysis and cytology are required for patients who had IVRF for 36 months or longer.

\section{Introduction}

Upper tract urothelial carcinoma (UTUC) is a urothelial cancer that occurs in the ureter or pelvocaliceal system, showing incidence occurring in 1-2 out of $100,000^{1,2}$. Recently, the incidence of UTUC has been increasing as diagnostic techniques, such as radiologic and endoscopic techniques, have been developed ${ }^{3}$. Although the etiology of UTUC is not yet clear, cigarette smoking, herbal medicines, chronic infection, and occupational carcinogenesis are known as risk factors for UTUC ${ }^{3}$. The gold standard treatment for UTUC is radical nephroureterectomy with bladder cuff excision (RNUx), which shows excellent oncological outcomes ${ }^{4}$. However, the most concerning part after RNUx is intravesical recurrence (IVR), where IVR occurs at $15-50 \%$ after RNUx ${ }^{5,6}$. The occurrence of IVR after RNUx is important because additional treatments such as surgery and chemotherapy due to bladder cancer are required, and it may affect the prognosis of UTUC ${ }^{7}$.

There are common to the same histological subtype and occur in the urothelium between UTUC and bladder cancer, although both are embryological, epidemiological, and molecular differences ${ }^{8}$. Because of this commonality, approximately $13 \%$ of UTUC patients have a previous history of bladder cancer, and approximately $9 \%$ of UTUCs are diagnosed at the same time as bladder cancer ${ }^{9}$. This also results in a high IVR rate after RNUx ${ }^{10}$.

Accurate assessment of risk factors for IVR after RNUx is important in reducing unnecessary examinations and treatments for bladder cancer ${ }^{11}$. Several previous studies have been conducted with the aim of evaluating and preventing IVR that occurs after RNUx. In these studies, tumor location, cancer stage, grade, and sex were reported as risk factors for IVR after RNUx ${ }^{7,12,13}$. However, there is not much evidence on the guide-line for IVR follow up. IVR is occurs most popularly within 1 year after RNUx ${ }^{14}$. Moreover, there are insufficient reports on the probability of recurrence or follow-up of IVR when there is no recurrence within 1 year or no IVR for a specific period. In particular, there is no report of IVR free survival for patients who did not have bladder cancer history or did not have concomitant bladder cancer with UTUC.

Therefore, this study evaluates the incidence and risk factors of IVR by analyzing a relatively large number of patients who underwent RNUx for UTUC. Moreover, conditional IVR free (IVRF) survival of the UTUC patient who had no bladder cancer history and no concomitant bladder cancer. 


\section{Patients And Methods}

\section{Patients and clinico-pathological parameters.}

We retrospectively analyzed 1095 patients who underwent RNUx for UTUC at single medical center from 1994 to 2018. All patients underwent either the standard open or minimal invasive surgery, and specimens collected were also evaluated at single institution. Preoperative ureteroscopic examination (URS) was not performed routinely. Lymph node dissection was not routinely performed on all patients but was underwent when lymph node invasion was suspected based on the radiologic evaluation. To evaluate the factors affecting IVR, the 1095 were divided into two groups of 462 patients with IVR and 633 without IVR.

Among 1095, 856 patients without bladder cancer history and without concomitant bladder cancer were assessed for additional analysis for conditional IVRF survival. To evaluate the IVRF survival, the 856 were divided into two groups of 536 patients with IVR and 320 without IVR.

Baseline characteristics were evaluated, including age, sex, body mass index (BMI), American Society of Anesthesiologists (ASA) score, smoking history, bladder tumor history, and underlying disease including hypertension (HTN) and diabetes mellitus (DM). In addition, the location, laterality, and multifocality of the UTUCs were analyzed to evaluate oncological outcomes, and surgical modality, approach methods, use of preoperative URS, TNM stage, and pathological outcomes were evaluated. Tumors were staged according to the 2010 American Joint Committee on Cancer/International Union Against Cancer TNM classification ${ }^{15}$. To evaluate conditional IVRF survival, sub-analysis was performed in patients with IVRF for $6,12,24,36,48$, and 60 months.

\section{Statistical analysis.}

The groups were compared using the chi-square test for categorical variables and the Student's $t$-test for continuous variables. Multivariable Cox regression analyses were performed to evaluate factors affecting IVR, and the IVRF survival rate was also analyzed using Kaplan-Meier curves. Statistical analyses were carried out using SPSS ${ }^{\circledR}$ software, version 21.0, and for all two-sided tests, $p<$ 0.05 was considered statistically significant.

\section{Ethics statement.}

The study was performed in agreement with applicable laws and regulations, good clinical practices, and ethical principles as described in the Declaration of Helsinki. The Institutional Review Board of the Samsung Medical Center approved the present study (IRB No. 2019-09-115-002). Informed consent was waived by the Board.

\section{Results}

Among 1,095 patients, 462 patients developed IVR. The mean age of patients with IVR was $64.88 \pm 10.35$ years, and the mean age of patients without IVR was $65.92 \pm 11.28$ years $(p=0.120)$. The prevalence rates of HTN and DM were $48.05 \%$ and $22.29 \%$, respectively, in the IVR group and $41.71 \%$ and $16.43 \%$, respectively, in the without IVR group (HTN: $p=0.037$, DM: $p=0.014$ ). A total of $30.74 \%$ of the IVR group and $15.32 \%$ of the without IVR group had a past history of bladder cancer $(p<0.001)$. Multifocal tumors were observed in $25.54 \%$ of the IVR group and $22.75 \%$ of the without IVR group $(p=0.003)$.

Cuffing was performed using the intravesical approach in $51.95 \%$ of the IVR group and $60.19 \%$ of the without IVR group $(p=0.007)$. Preoperative URS was performed in $59.53 \%$ of the IVR group and in $44.39 \%$ of the without IVR group $(p<0.001)$. Adjuvant chemotherapy was performed in 81 patients $(17.53 \%)$ in the IVR group and 159 patients $(25.12 \%)$ in the without IVR group $(p<0.001)$ (Table 1). 
Table 1

Baseline characteristics and operative and pathological outcomes.

\begin{tabular}{|c|c|c|c|}
\hline & IVR group, $n=462$ & Non-IVR group, $n=633$ & $p$ value \\
\hline Age, yr & $64.88 \pm 10.35$ & $65.92 \pm 11.28$ & 0.120 \\
\hline Sex, male, n (\%) & $352(76.19)$ & 454 (71.72) & $0.098^{a}$ \\
\hline $\mathrm{BMI}, \mathrm{kg} / \mathrm{m}^{2}$ & $24.40 \pm 3.32$ & $24.21 \pm 3.00$ & 0.322 \\
\hline ASA score, $\leq 2, \mathrm{n}(\%)$ & $415(89.83)$ & $572(90.36)$ & $0.116^{\mathrm{a}}$ \\
\hline HTN & $222(48.05)$ & $264(41.71)$ & $0.037^{a}$ \\
\hline DM & $103(22.29)$ & $104(16.43)$ & $0.014^{a}$ \\
\hline Smoking, never-smoker, n (\%) & $215(46.54)$ & $297(46.92)$ & $0.771^{\mathrm{a}}$ \\
\hline Ex-smoker & $134(29.00)$ & $176(27.80)$ & \\
\hline Current smoker & $111(24.03)$ & $154(24.33)$ & \\
\hline Gross hematuria & $369(79.87)$ & $475(75.04)$ & $0.060^{\mathrm{a}}$ \\
\hline History of bladder tumor & $142(30.74)$ & 97 (15.32) & $<0.001^{a}$ \\
\hline Laterality & & & $0.159^{a}$ \\
\hline Left & $239(51.73)$ & $360(56.87)$ & \\
\hline Right & $223(48.27)$ & $272(42.97)$ & \\
\hline Tumor location & & & $0.057^{a}$ \\
\hline Renal pelvis & $188(40.69)$ & $302(47.71)$ & \\
\hline Ureter & $217(46.97)$ & $269(42.50)$ & \\
\hline Both renal pelvis and ureter & $57(12.34)$ & $62(9.79)$ & \\
\hline Multi-focal tumor, n (\%) & $118(25.54)$ & $114(22.75)$ & $0.003^{\mathrm{a}}$ \\
\hline Surgical modality, n (\%) & & & $0.395^{a}$ \\
\hline MIS & $242(52.38)$ & $348(54.98)$ & \\
\hline Open & $220(47.62)$ & $285(45.02)$ & \\
\hline Extravesical bladder cuffing, $n(\%)$ & $222(48.05)$ & $252(39.81)$ & $0.007^{a}$ \\
\hline Preoperative ureteroscopy, n (\%) & $275(59.53)$ & 281(44.39) & $<0.001^{a}$ \\
\hline pT stage, n (\%) & & & $<0.001^{\mathrm{a}}$ \\
\hline pTa & $62(13.42)$ & $73(11.53)$ & \\
\hline pT1 & $147(31.82)$ & $175(27.65)$ & \\
\hline pT2 & $94(20.35)$ & $90(14.22)$ & \\
\hline рT3-рT4 & $159(34.42)$ & $295(46.60)$ & \\
\hline Grade, n (\%) & & & $0.002^{\mathrm{a}}$ \\
\hline Grade 3 & $191(41.34)$ & $315(49.76)$ & \\
\hline Concomitant CIS, n (\%) & $52(11.26)$ & $70(11.06)$ & $0.906^{\mathrm{a}}$ \\
\hline
\end{tabular}




\begin{tabular}{|c|c|c|c|}
\hline & IVR group, $n=462$ & Non-IVR group, $n=633$ & $p$ value \\
\hline Lymph node, n (\%) & & & $<0.001^{\mathrm{a}}$ \\
\hline pNO & $97(21.00)$ & $179(28.28)$ & \\
\hline pN1 & $26(5.63)$ & $75(11.85)$ & \\
\hline $\mathrm{pNx}$ & $339(73.38)$ & $379(59.87)$ & \\
\hline Tumor size, $\mathrm{cm}$ & $3.81 \pm 3.15$ & $3.91 \pm 2.84$ & 0.578 \\
\hline Lymphovascular invasion, $\mathrm{n}(\%)$ & $78(16.88)$ & $133(21.01)$ & $0.087^{\mathrm{a}}$ \\
\hline Surgical margin positive, $\mathrm{n}(\%)$ & $26(5.63)$ & $22(3.48)$ & $0.086^{a}$ \\
\hline Adjuvant chemotherapy, n (\%) & $81(17.53)$ & $159(25.12)$ & $0.003^{a}$ \\
\hline Follow up, months & $60.14 \pm 51.68$ & $44.37 \pm 45.54$ & $<0.001$ \\
\hline \multicolumn{4}{|c|}{$\begin{array}{l}\text { IVR = intravesical recurrence; BMI = body mass index; } \mathrm{ASA}=\text { American Society of Anesthesiologists; HTN = hypertension; DM = } \\
\text { diabetes mellitus; MIS = minimal invasive surgery; CIS = carcinoma in situ. }\end{array}$} \\
\hline
\end{tabular}

The IVR occurred with a mean 13.08 (interquartile range, 3.97-14.05) months to recurrence. The mean IVR-free survival period was 59.86 (8.72) months in patients with a previous history or bladder cancer history, and 136.84 (5.92) months in patients without such history $(p<0.001)$ (Fig. 1).

We assessed the impact on IVRF survival of each risk factor for IVR deemed significant in the multivariable analysis in patients without bladder cancer history. In the multivariable analysis, previous bladder cancer history $(H R=2.409, p<0.001)$, a multifocal tumor ( $\mathrm{HR}=1.348, p=0.008)$, use of preoperative URS ( $\mathrm{HR}=1.733, p<0.001)$, extravesical bladder cuffing $(\mathrm{HR}=1.408, p=0.009)$, lymph node involvement $(H R=2.121, p=0.004)$, positive margins $(H R=1.553, p=0.026)$, and adjuvant chemotherapy $(H R=0.759, p$ $=0.033$ ) were found to affect IVR (Table 2). The mean IVRF survival rate at 5-year after RNUx was $49.3(0.05) \%$ for multifocal tumors and $56.2(0.02) \%$ for solitary tumors $(p=0.008)$. The mean IVRF survival rate at 5 -year after surgery was $45.0(0.03) \%$ for those with preoperative URS and $65.7(0.03) \%$ for those without preoperative URS $(p<0.001)$. In the case of lymph node involvement, the mean IVRF survival rate at 5-year after RNU/BCE was $58.5(0.12) \%$ and $66.1(0.04) \%$ for patients with and without involvement, respectively $(p<0.001)$. At 5 -year after surgery the mean IVRF survival rate of the intravesical bladder-cuffing group was $59.9(0.03) \%$, and the extravesical bladder-cuffing group was $49.3(0.03) \%(p=0.001)$ (Fig. 2). 
Table 2

Univariable and multivariable Cox regression analyses.

\begin{tabular}{|c|c|c|c|c|c|c|}
\hline & \multicolumn{3}{|c|}{ Univariable } & \multicolumn{3}{|c|}{ Multivariable } \\
\hline & HR & $95 \% \mathrm{Cl}$ & $p$ value & HR & $95 \% \mathrm{Cl}$ & $\mathrm{p}$ value \\
\hline Age (continuous) & 1.016 & $1.007-1.025$ & 0.001 & 1.000 & $0.988-1.013$ & 0.959 \\
\hline Sex, male & 1.108 & $0.894-1.373$ & 0.348 & & & \\
\hline BMI & 0.985 & $0.957-1.014$ & 0.302 & & & \\
\hline DM & 1.424 & $1.143-1.773$ & 0.002 & 1.279 & $0.912-1.794$ & 0.154 \\
\hline HTN & 1.248 & $1.040-1.498$ & 0.017 & 1.294 & $0.975-1.717$ & 0.074 \\
\hline Gross hematuria & 1.148 & $0.914-1.441$ & 0.235 & & & \\
\hline Smoking & 0.949 & $0.851-1.057$ & 0.342 & & & \\
\hline Bladder cancer history & 2.184 & $1.791-2.665$ & $<0.001$ & 2.409 & $1.761-3.297$ & $<0.001$ \\
\hline ASA score & 1.229 & $1.050-1.438$ & 0.010 & 1.112 & $0.861-1.436$ & 0.417 \\
\hline Laterality & 0.868 & $0.723-1.041$ & 0.127 & & & \\
\hline \multicolumn{7}{|l|}{ Location } \\
\hline Renal pelvis & 1 & reference & - & & & \\
\hline Ureter & 1.211 & $0.996-1.473$ & 0.055 & & & \\
\hline Both & 1.487 & $1.108-1.997$ & 0.008 & 1.055 & $0.610-1.824$ & 0.849 \\
\hline Multifocality & 1.503 & $1.219-1.853$ & $<0.001$ & 1.348 & $1.082-1.678$ & 0.008 \\
\hline Preoperative URS & 1.597 & $1.325-1.925$ & $<0.001$ & 1.733 & $1.338-2.244$ & $<0.001$ \\
\hline \multicolumn{7}{|l|}{ Operation modality } \\
\hline MIS & 0.859 & $0.454-1.624$ & 0.640 & & & \\
\hline Bladder cuffing, extravesical & 1.320 & $1.099-1.585$ & 0.003 & 1.408 & $1.090-1.818$ & 0.009 \\
\hline \multicolumn{7}{|l|}{ pT stage } \\
\hline pTa & 1 & reference & - & & & \\
\hline pT1 & 1.164 & $0.867-1.561$ & 0.312 & & & \\
\hline pT2 & 1.311 & $1.047-1.641$ & 0.018 & & & \\
\hline $\mathrm{pT} 3+4$ & 1.492 & $1.156-1.926$ & 0.002 & 1.245 & $0.958-1.619$ & 0.102 \\
\hline Grade, low grade & 0.902 & $0.781-1.041$ & 0.158 & & & \\
\hline Concomitant CIS & 0.977 & $0.743-1.285$ & 0.870 & & & \\
\hline \multicolumn{7}{|l|}{ Lymph node positive } \\
\hline pNO & 1 & reference & - & & & \\
\hline
\end{tabular}

$\mathrm{HR}=$ hazard ratio; $\mathrm{Cl}$ = confidence interval; $\mathrm{BMI}=$ body mass index; $\mathrm{DM}=$ diabetes mellitus; $\mathrm{HTN}=$ hypertension; $\mathrm{CVA}=$ cerebrovascular accident; ASA = American society of anesthesiologists; URS = ureteroscopic examination; CIS = carcinoma in situ. 


\begin{tabular}{|c|c|c|c|c|c|c|}
\hline & \multicolumn{3}{|c|}{ Univariable } & \multicolumn{3}{|c|}{ Multivariable } \\
\hline & HR & $95 \% \mathrm{Cl}$ & $p$ value & HR & $95 \% \mathrm{Cl}$ & $p$ value \\
\hline $\mathrm{pN} 1$ & 1.651 & $1.238-2.200$ & 0.001 & 2.121 & $1.274-3.532$ & 0.004 \\
\hline $\mathrm{pNx}$ & 0.640 & $0.384-1.065$ & 0.086 & & & \\
\hline Tumor size & 1.009 & $0.975-1.044$ & 0.602 & & & \\
\hline Margin positive & 2.009 & $1.350-2.988$ & $<0.001$ & 1.553 & $0.819-2.947$ & 0.026 \\
\hline Lymphovascular invasion & 0.927 & $0.727-1.183$ & 0.545 & & & \\
\hline Adjuvant chemotherapy & 0.697 & $0.548-0.886$ & 0.003 & 0.759 & $0.589-0.979$ & 0.033 \\
\hline
\end{tabular}

\section{Conditional IVRF survival in the UTUC patients who dad no bladder cancer history or concomitant bladder cancer.}

The IVRF rate at 12 months after RNUx was $74.0 \%$, for those who IVRF for 12 months, the IVRF rate was $87.1 \%$ for the next 12 months (24 months after RNUx), and for the patients who IVRF for 24 months, the IVRF rate was $93.6 \%$ for the next 12 months (36 months after RNUx) and the IVRF rate was $97.3 \%$ for the next 12 months in IVRF of 60 months patients (Fig. 3). The mean IVRF survival period of all patients was 136.84 months, 156.24 months in the patients with 6 months IVRF, 175.38 months for the patients with 12 months IVRF, 189.14 months for the patients with 36 months IVRF, and mean IVRF survival period was 178.21 months in 60 months IVRF patients (Table 3).

Table 3

Conditional intravesical recurrence free survival after radical nephroureterectomy with bladder cuff excision.

\begin{tabular}{|llllllll|}
\hline Conditional IVR free period & Total & $\mathbf{6}$ months & $\mathbf{1}$ year & $\mathbf{2}$ years & $\mathbf{3}$ years & $\mathbf{4}$ years & $\mathbf{5}$ years \\
\hline No. of patients & 856 & 696 & 544 & 381 & 285 & 228 & 174 \\
\hline Intravesical recurrence, $n(\%)$ & 320 & 205 & 111 & 47 & $25(8.77)$ & $16(7.02)$ & $9(5.17)$ \\
& $(37.38)$ & $(29.45)$ & $(20.40)$ & $(12.34)$ & & & \\
\hline $\begin{array}{l}\text { Mean IVR free survival, month } \\
\text { (standard error) }\end{array}$ & 136.84 & 156.24 & 175.38 & 188.67 & 189.14 & 183.84 & 178.21 \\
\hline $\begin{array}{l}5 \text { years IVR free rate, \% (standard } \\
\text { error) }\end{array}$ & $(5.92)$ & $(6.34)$ & $(6.83)$ & $(7.07)$ & $(7.03)$ & $(6.92)$ & $(6.73)$ \\
\hline $\begin{array}{l}\text { 10 years IVR free rate, \% (standard } \\
\text { error) }\end{array}$ & $(0.02)$ & $(0.02)$ & $(0.02)$ & $(0.02)$ & $(0.03)$ & $(0.02)$ & $(0.02)$ \\
\hline${ }^{*}$ After conditional IVR free period. & $(0.02)$ & $(0.02)$ & $(0.03)$ & $(0.03)$ & $(0.03)$ & $(0.03)$ & $(0.03)$ \\
\hline
\end{tabular}

Multivariable Cox regression analysis DM (HR 1.589, $p=0.017$ ), gross hematuria (HR 1.744, $p=0.003$ ), URS (HR 2.207, $p<0.001$ ), and extravesical bladder cuff excision (HR 1.614, $p=0.002$ ) were evaluated to independently affect IVR. In 24 months IVRF patients after RNUx, only URS was evaluated to independently affect IVR (HR 1.945, $p=0.040)$. In patients with 36 months or more IVRF, there was no significant factor affecting IVR (Table 4). 
Table 4

Risk factors of IVR in the UTUC patients who had no bladder cancer history.

\begin{tabular}{|c|c|c|c|c|c|c|c|c|c|c|c|c|}
\hline & \multicolumn{3}{|l|}{ Total } & \multicolumn{3}{|c|}{6 months IVRF } & \multicolumn{3}{|c|}{12 months IVRF } & \multicolumn{3}{|c|}{24 months IVRF } \\
\hline & HR & $95 \% \mathrm{Cl}$ & $\mathrm{p}_{\text {value }}$ & HR & $95 \% \mathrm{Cl}$ & $\begin{array}{l}p \\
\text { value }\end{array}$ & HR & $95 \% \mathrm{Cl}$ & $\begin{array}{l}p \\
\text { value }\end{array}$ & HR & $95 \% \mathrm{Cl}$ & $\begin{array}{l}\mathbf{p} \\
\text { value }\end{array}$ \\
\hline $\begin{array}{l}\text { Diabetes } \\
\text { mellitus }\end{array}$ & 1.589 & $\begin{array}{l}1.088- \\
2.323\end{array}$ & 0.017 & 1.281 & $\begin{array}{l}0.814- \\
2.017\end{array}$ & 0.284 & 1.105 & $\begin{array}{l}0.609- \\
2.002\end{array}$ & 0.743 & 1.173 & $\begin{array}{l}0.484- \\
2.841\end{array}$ & 0.724 \\
\hline $\begin{array}{l}\text { Gross } \\
\text { hematuria }\end{array}$ & 1.744 & $\begin{array}{l}1.209- \\
2.515\end{array}$ & 0.003 & 2.258 & $\begin{array}{l}1.425- \\
3.580\end{array}$ & 0.001 & 2.299 & $\begin{array}{l}1.252- \\
4.219\end{array}$ & 0.007 & 2.083 & $\begin{array}{l}0.881- \\
4.926\end{array}$ & 0.095 \\
\hline $\begin{array}{l}\text { Ureteroscopic } \\
\text { examination }\end{array}$ & 2.207 & $\begin{array}{l}1.633- \\
2.985\end{array}$ & $<.001$ & 2.14 & $\begin{array}{l}1.502- \\
3.049\end{array}$ & $\begin{array}{l}< \\
0.001\end{array}$ & 2.082 & $\begin{array}{l}1.324- \\
3.274\end{array}$ & 0.001 & 1.945 & $\begin{array}{l}1.030- \\
3.672\end{array}$ & 0.040 \\
\hline $\begin{array}{l}\text { Bladder } \\
\text { cuffing, } \\
\text { extravesical }\end{array}$ & 1.614 & $\begin{array}{l}1.193- \\
2.183\end{array}$ & 0.002 & 1.557 & $\begin{array}{l}1.091- \\
2.220\end{array}$ & 0.015 & 1.336 & $\begin{array}{l}0.847- \\
2.105\end{array}$ & 0.213 & 1.208 & $\begin{array}{l}0.624- \\
2.341\end{array}$ & 0.575 \\
\hline Grade & 0.77 & $\begin{array}{l}0.589- \\
1.007\end{array}$ & 0.057 & 0.643 & $\begin{array}{l}0.466- \\
0.887\end{array}$ & 0.007 & 0.595 & $\begin{array}{l}0.394- \\
0.900\end{array}$ & 0.014 & 0.683 & $\begin{array}{l}0.384- \\
1.215\end{array}$ & 0.194 \\
\hline \multirow[t]{3}{*}{$\begin{array}{l}\text { Adjuvant } \\
\text { chemotherapy }\end{array}$} & 0.746 & $\begin{array}{l}0.510- \\
1.092\end{array}$ & 0.131 & 1.253 & $\begin{array}{l}0.819- \\
1.917\end{array}$ & 0.298 & 1.407 & $\begin{array}{l}0.808- \\
2.448\end{array}$ & 0.227 & 1.671 & $\begin{array}{l}0.773- \\
3.612\end{array}$ & 0.192 \\
\hline & \multicolumn{3}{|c|}{36 months IVRF } & \multicolumn{3}{|c|}{48 months IVRF } & \multicolumn{3}{|c|}{60 months IVRF } & & & \\
\hline & HR & $95 \% \mathrm{Cl}$ & $p_{\text {value }}$ & $\mathrm{HR}$ & $95 \% \mathrm{Cl}$ & $\begin{array}{l}\mathrm{p} \\
\text { value }\end{array}$ & HR & $95 \% \mathrm{Cl}$ & $\begin{array}{l}\mathrm{p} \\
\text { value }\end{array}$ & & & \\
\hline $\begin{array}{l}\text { Diabetes } \\
\text { mellitus }\end{array}$ & 1.237 & $\begin{array}{l}0.337- \\
4.535\end{array}$ & 0.749 & 2.213 & $\begin{array}{l}0.563- \\
8.704\end{array}$ & 0.255 & 1.137 & $\begin{array}{l}0.126- \\
10.294\end{array}$ & 0.909 & & & \\
\hline $\begin{array}{l}\text { Gross } \\
\text { hematuria }\end{array}$ & 1.088 & $\begin{array}{l}0.408- \\
2.903\end{array}$ & 0.866 & 0.638 & $\begin{array}{l}0.201- \\
2.018\end{array}$ & 0.444 & 0.945 & $\begin{array}{l}0.168- \\
5.309\end{array}$ & 0.948 & & & \\
\hline $\begin{array}{l}\text { Ureteroscopic } \\
\text { examination }\end{array}$ & 1.688 & $\begin{array}{l}0.724- \\
3.935\end{array}$ & 0.225 & 1.548 & $\begin{array}{l}0.532- \\
4.505\end{array}$ & 0.422 & 1.632 & $\begin{array}{l}0.388- \\
6.861\end{array}$ & 0.504 & & & \\
\hline $\begin{array}{l}\text { Bladder } \\
\text { cuffing, } \\
\text { extravesical }\end{array}$ & 0.858 & $\begin{array}{l}0.349- \\
2.109\end{array}$ & 0.738 & 0.427 & $\begin{array}{l}0.112- \\
1.634\end{array}$ & 0.214 & 0.79 & $\begin{array}{l}0.139- \\
4.509\end{array}$ & 0.791 & & & \\
\hline Grade & 0.717 & $\begin{array}{l}0.332- \\
1.549\end{array}$ & 0.398 & 0.816 & $\begin{array}{l}0.311- \\
2.144\end{array}$ & 0.680 & 0.848 & $\begin{array}{l}0.228- \\
3.160\end{array}$ & 0.806 & & & \\
\hline $\begin{array}{l}\text { Adjuvant } \\
\text { chemotherapy }\end{array}$ & 1.493 & $\begin{array}{l}0.526- \\
4.242\end{array}$ & 0.452 & 0.991 & $\begin{array}{l}0.248- \\
3.967\end{array}$ & 0.991 & 0.618 & $\begin{array}{l}0.067- \\
5.708\end{array}$ & 0.671 & & & \\
\hline \multicolumn{13}{|c|}{ Multivariable Cox regression analysis. } \\
\hline
\end{tabular}

\section{Discussion}

In this study, the risk factors of IVR after RNUx were presented with UTUC. Moreover, it could be confirmed that patients who had no significant affecting UTUC-related factor to IVR in the patients who had 36 months or over IVRF. However, it was confirmed that about $5 \%$ of patients with an IVRF period of 36 months or longer develop IVR.

After RNUx for UTUC, the cause of IVR is not clear, yet. However, the field theory that UTUC is exposed to the urothelium to generate $\mathrm{IVR}^{16}$, and the intraluminal tumor seeding theory that the upper tract's cancer cells are exposed to the bladder by the urinary stream ${ }^{17}$ are suggested as mechanisms of IVR. When URS is performed before RNUx, intraluminal pressure of the renal pelvis increases and tumor manipulation occurs, resulting in increased intraluminal tumor seeding and eventually increased IVR ${ }^{18,19}$. In present study, it was also evaluated that URS before RNUx is a risk factor to IVR in 0 to 24 IVRF patients. 
In a recent meta-analysis, the predictors of IVR were classified into three categories: patient-specific factors, tumor-specific factors, and treatment-specific factors ${ }^{20}$. In this study, patient-specific factors were male, previous bladder cancer history, chronic kidney disease, tumor-specific factors were positive urinary cytology, ureteral location, multifocality, invasive pT stage, necrosis, and treatment-specific factors were laparoscopic surgery, extravesical bladder cuff excision, positive surgical margins were reported as predictive factors for IVR. In present study, bladder cancer history, pre-operative URS, pre-operative URS, multifocality, LN invasion, bladder cuffing and surgical margin involvement were evaluated as risk factors of IVR after RNUx. Otherwise, present study was also conducted in patients with no previous bladder cancer history, in these patients, DM, gross hematuria, URS, and extravesical bladder cuff excision were evaluated as predictive factors of IVR after RNUx. This may come from the difference between the groups. However, it is clear that avoiding pre-operative URS and extravesical bladder cuff excision can reduce IVR.

Due to concerns about IVR, bladder examination including cystoscope and urinary cytology is recommended for 5 years after RNUx with UTUC ${ }^{4}$. However, due to the lack of studies, optimal follow-up strategies for IVR after RNUx cannot be concluded ${ }^{21,22}$. Recently, Shigeta et al. reported on conditional IVRF survival after RNUx of the 364 Ta-T3 UTUC patients ${ }^{23}$. According to this study, IVR was identified in $48.4 \%$ patients, and 5-year conditional IVRF survival rate increased from $41.5-60.5 \%, 73.4 \%, 79.5 \%$ and $96.7 \%$ in $1,2,3$ and 4-year IVRF patients, respectively. In present study, each conditional IVRF survival was evaluated for 0.5, 1, 2, 3, 4 and 5 year IVRF patients, and similar results were confirmed to previous study. Moreover, gross hematuria, URS, retroperitoneal approach, and low grade were identified as risk factors for IVR in the 12 months IVRF patients, and only URS was evaluated as a risk factor for IVR in the 24 months IVRF patients. In addition, for patients with IVRF over 36 months, these risk factors were judged to have no significant effect on IVR. However, IVR occurred in 13.1\% of patients with 36 months IVRF, and $5.6 \%$ of patients with 60 months IVRF were diagnosed with IVR. Although these cannot be clearly identified as IVR associated with UTUC, it was found to be higher than incidence of general population. These results show that UTUC patients requires IVR follow-up even after 5 years after RNUx.

Conditional survival analysis is a method of assessing additional survival at a specific time point after initial diagnosis or treatment ${ }^{24}$. Conditional survival is widely used in cancer research because it can transmit additional important and various information during follow-up ${ }^{25,26}$. In this study, conditional IVRF survival according to IVRF period was showed in a large number of UTUC patients without bladder cancers history. According the conditional IVRF survival rate of present study, in the case of patients whose IVRF period is less than 36 months, the rate of IVR occurrence after the IVRF period is more than $10 \%$, so active assessment is required until 36 months after RNUx. In addition, since IVR occurs in 3-5\% of patients with an IVRF period of 36 months or longer, patient education and screening test such as regular urine analysis and cytology are required.

The limitation of this study is that, as a retrospective study, it could not use fixed criteria in terms of diagnosis, treatment, and patient follow up. Second, the indications for the use of URS, lymphadenectomy, and adjuvant chemotherapy were not clear. Although this study cannot suggest an optimal follow-up strategy for IVR after RNUx to UTUC, it is considered that follow-up for IVR can be optimized through systematic analysis if additional data are collected in the future. Moreover, it is significant that it is the first report on conditional survival in a large-scale UTUC people without bladder cancer history.

\section{Conclusion}

In this study, previous bladder cancer history, multifocal tumors, pre-operative URS, lymph node invasion, extravesical bladder cuffing, and surgical margin involvement were identified as risk factors for IVR. However, in patients with no history of bladder cancer, DM, gross hematuria, pre-operative URS, and extravesical bladder cuffing were risk factors. In patients whose IVRF period is less than 36 months, the rate of IVR occurrence is $10 \%$ or more, active IVR assessment is required until 36 months after RNUx. In addition, since 3$5 \%$ of patients with an IVRF period of 36 months or longer develop IVR, patient education and regular screening test such as urine analysis and cytology are required for patients who had IVRF for 36 months or longer.

\section{Declarations}

\section{Author Contributions:}

Conceptualization, H.H.S.; methodology, W.S., M.K., H.G.J., B.C.J., S.I.S., S.S.J., H.M.L.; formal analysis, J.H.C.; data curation, J.H.C., H.H.S.; writing-original draft preparation, J.H.C.; writing-review and editing, H.H.S.; supervision, H.H.S.; All authors have read and agreed to the published version of the manuscript. 


\section{Funding:}

This research received no external funding.

\section{Conflicts of Interest:}

No potential conflicts of interest relevant to this article have been reported.

\section{References}

1. Siegel, R. L., Miller, K. D. \& Jemal, A. Cancer statistics, 2020. CA Cancer J. Clin. 70, 7-30, http://doi.org/10.3322/caac.21590 (2020).

2. Soria, F. et al. Epidemiology, diagnosis, preoperative evaluation and prognostic assessment of upper-tract urothelial carcinoma (UTUC). World J. Urol. 35, 379-387, http://doi.org/10.1007/s00345-016-1928-x (2017).

3. Raman, J. D., Messer, J., Sielatycki, J. A. \& Hollenbeak, C. S. Incidence and survival of patients with carcinoma of the ureter and renal pelvis in the USA, 1973-2005. BJU Int. 107, 1059-1064, http://doi.org/10.1111/j.1464-410X.2010.09675.x (2011).

4. Rouprêt, M. et al. European Association of Urology Guidelines on Upper Urinary Tract Urothelial Carcinoma: 2017 Update. Eur. Urol. 73, 111-122, http://doi.org/10.1016/j.eururo.2017.07.036 (2018).

5. Margulis, V. et al. Outcomes of radical nephroureterectomy: a series from the Upper Tract Urothelial Carcinoma Collaboration. Cancer 115, 1224-1233, http://doi.org/10.1002/cncr.24135 (2009).

6. Kikuchi, E. \& Oya, M. Clinical practice patterns for upper tract urothelial carcinoma: a nationwide survey in Japan. Jpn. J. Clin. Oncol. 46, 768-774, http://doi.org/10.1093/jjco/hyw072 (2016).

7. Xylinas, E. et al. Intravesical recurrence after radical nephroureterectomy for upper tract urothelial carcinomas: predictors and impact on subsequent oncological outcomes from a national multicenter study. World J. Urol. 31, 61-68, http://doi.org/10.1007/s00345-012-0957-3 (2013).

8. Green, D. A. et al. Urothelial carcinoma of the bladder and the upper tract: disparate twins. J. Urol. 189, 1214-1221, http://doi.org/10.1016/j.juro.2012.05.079 (2013).

9. Pignot, G. et al. Influence of previous or synchronous bladder cancer on oncologic outcomes after radical nephroureterectomy for upper urinary tract urothelial carcinoma. Urol. Oncol. 32, 23 e21-28, http://doi.org/10.1016/j.urolonc.2012.08.010 (2014).

10. Yamashita, S. et al. Clinical implications of intravesical recurrence after radical nephroureterectomy for upper urinary tract urothelial carcinoma. Int. J. Urol. 23, 378-384, http://doi.org/10.1111/iju.13054 (2016).

11. Lee, C. H. et al. Predictors for Intravesical Recurrence Following Radical Nephroureterectomy for Upper Tract Urothelial Carcinoma: A National Multicenter Analysis. Clin. Genitourin. Cancer 15, e1055-e1061, http://doi.org/10.1016/j.clgc.2017.07.009 (2017).

12. Zigeuner, R. E., Hutterer, G., Chromecki, T., Rehak, P. \& Langner, C. Bladder tumour development after urothelial carcinoma of the upper urinary tract is related to primary tumour location. BJU Int. 98, 1181-1186, http://doi.org/10.1111/j.1464410X.2006.06519.x (2006).

13. Azemar, M. D., Comperat, E., Richard, F., Cussenot, O. \& Roupret, M. Bladder recurrence after surgery for upper urinary tract urothelial cell carcinoma: frequency, risk factors, and surveillance. Urol. Oncol. 29, 130-136, http://doi.org/10.1016/j.urolonc.2009.06.003 (2011).

14. Raman, J. D. et al. Bladder cancer after managing upper urinary tract transitional cell carcinoma: predictive factors and pathology. BJU Int. 96, 1031-1035, http://doi.org/10.1111/j.1464-410X.2005.05804.x (2005).

15. Edge, S. B. \& Compton, C. C. The American Joint Committee on Cancer: the 7th edition of the AJCC cancer staging manual and the future of TNM. Ann. Surg. Oncol. 17, 1471-1474, http://doi.org/10.1245/s10434-010-0985-4 (2010).

16. Jones, T. D. et al. Molecular evidence supporting field effect in urothelial carcinogenesis. Clin Cancer Res. 11, 6512-6519, http://doi.org/10.1158/1078-0432.Ccr-05-0891 (2005).

17. Habuchi, T. et al. Metachronous multifocal development of urothelial cancers by intraluminal seeding. Lancet 342, 1087-1088, http://doi.org/10.1016/0140-6736(93)92066-3 (1993).

Page 10/14 
18. Kang, C. H. et al. The development of bladder tumors and contralateral upper urinary tract tumors after primary transitional cell carcinoma of the upper urinary tract. Cancer 98, 1620-1626, http://doi.org/10.1002/cncr.11691 (2003).

19. Tan, P. et al. Diagnostic Ureteroscopy Prior to Radical Nephroureterectomy for Upper Tract Urothelial Carcinoma Increased the Risk of Intravesical Recurrence. Urol. Int. 100, 92-99, http://doi.org/10.1159/000484417 (2018).

20. Seisen, T. et al. A Systematic Review and Meta-analysis of Clinicopathologic Factors Linked to Intravesical Recurrence After Radical Nephroureterectomy to Treat Upper Tract Urothelial Carcinoma. Eur. Urol. 67, 1122-1133, http://doi.org/10.1016/j.eururo.2014.11.035 (2015).

21. Xylinas, E. et al. Prediction of intravesical recurrence after radical nephroureterectomy: development of a clinical decision-making tool. Eur. Urol. 65, 650-658, http://doi.org/10.1016/j.eururo.2013.09.003 (2014).

22. Ishioka, J. et al. Risk stratification for bladder recurrence of upper urinary tract urothelial carcinoma after radical nephroureterectomy. BJU Int. 115, 705-712, http://doi.org/10.1111/bju.12707 (2015).

23. Shigeta, K. et al. The Conditional Survival with Time of Intravesical Recurrence of Upper Tract Urothelial Carcinoma. J. Urol. 198, 1278-1285, http://doi.org/10.1016/j.juro.2017.06.073 (2017).

24. Zabor, E. C., Gonen, M., Chapman, P. B. \& Panageas, K. S. Dynamic prognostication using conditional survival estimates. Cancer 119, 3589-3592, http://doi.org/10.1002/cncr.28273 (2013).

25. Harshman, L. C. et al. Conditional survival of patients with metastatic renal-cell carcinoma treated with VEGF-targeted therapy: a population-based study. Lancet Oncol. 13, 927-935, http://doi.org/10.1016/s1470-2045(12)70285-1 (2012).

26. Leitner, C. V. et al. Dynamic Prognostication Using Conditional Recurrence and Progression Estimates for Patients with Nonmuscle Invasive Bladder Cancer. J. Urol. 196, 46-51, http://doi.org/10.1016/j.juro.2016.01.102 (2016).

\section{Figures}




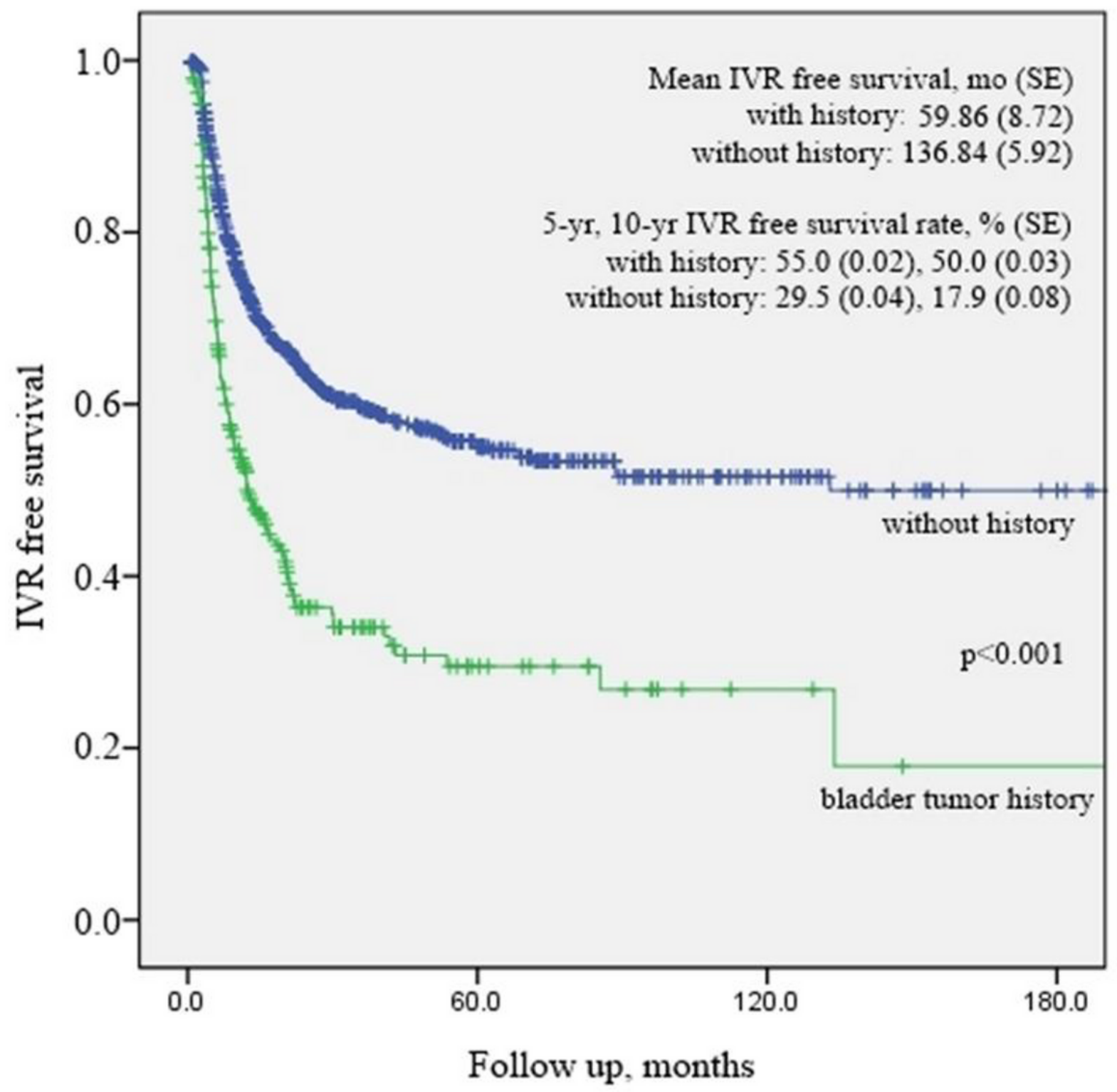

Figure 1

Kaplan-Meier curve for intravesical tumor recurrence according previous bladder cancer history. 
(a)

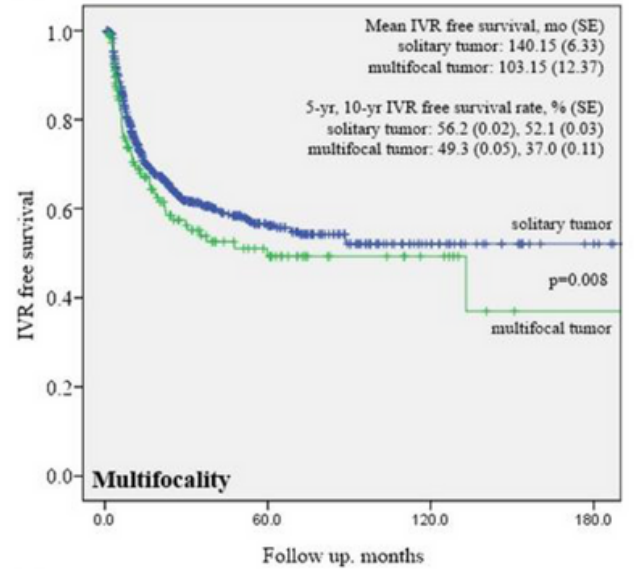

(d)

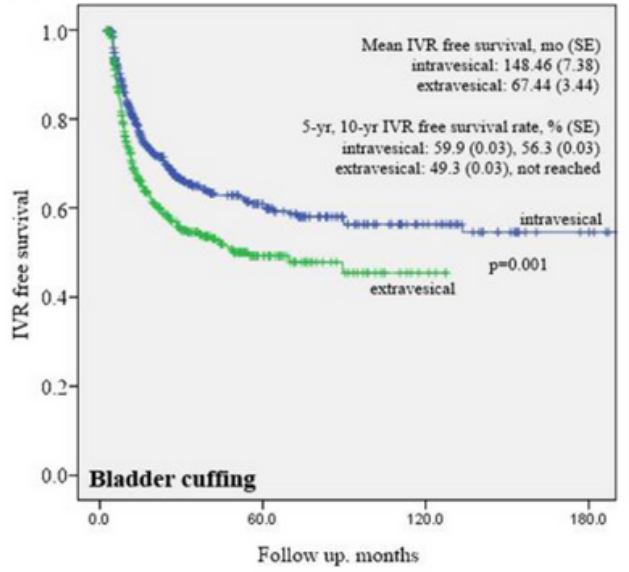

(b)

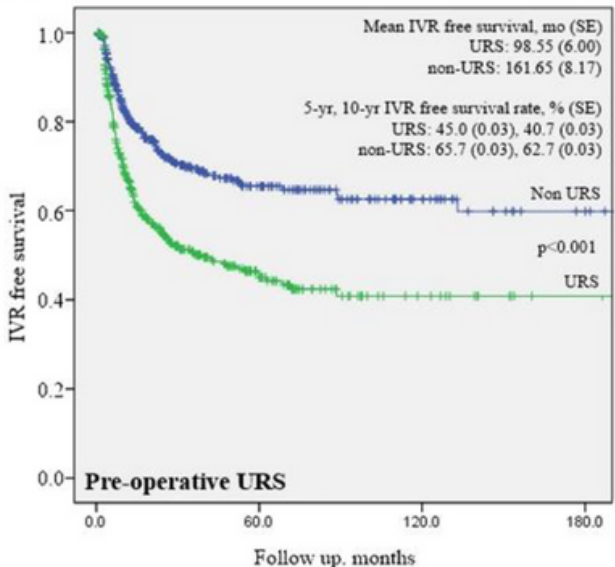

(e)

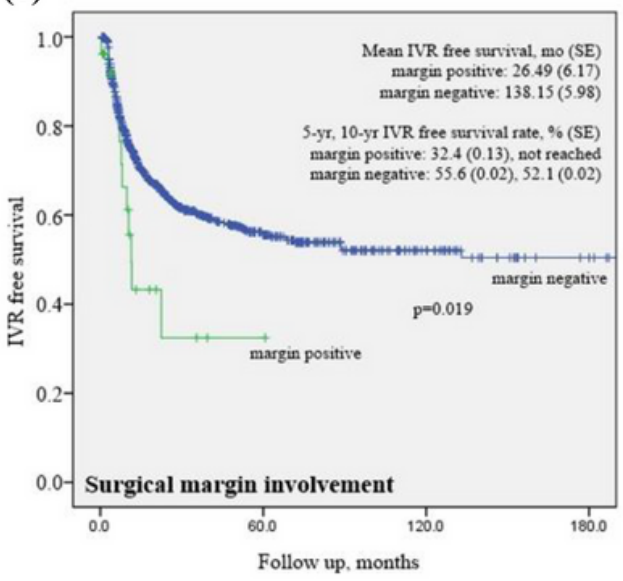

(c)

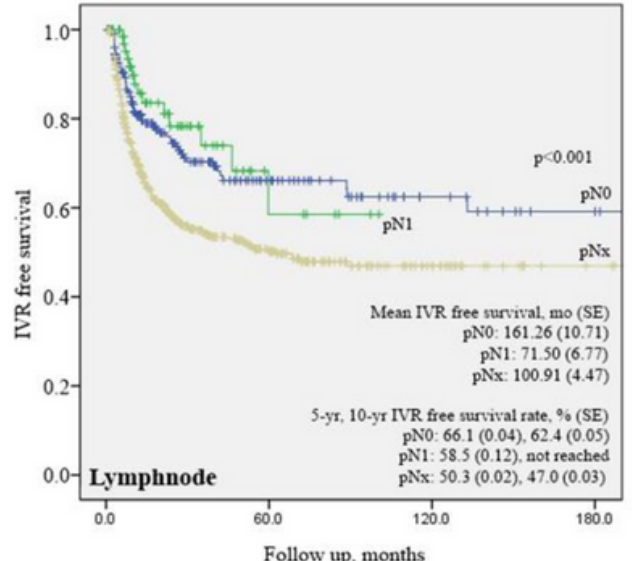

(f)

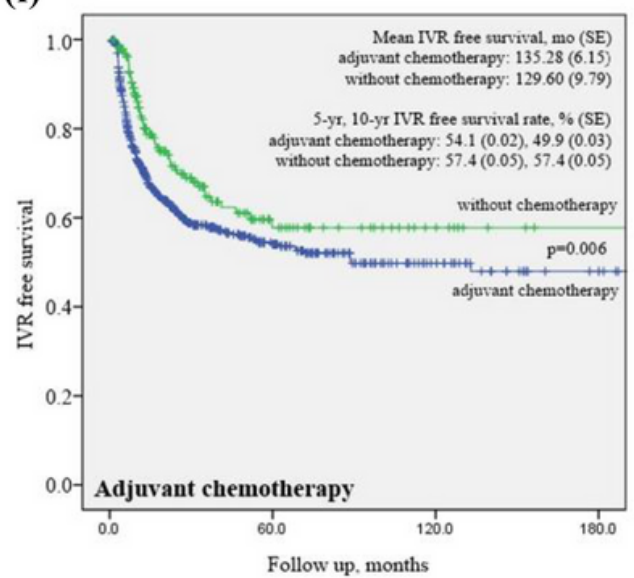

Figure 2

Kaplan-Meier curve for intravesical recurrence in the patients without previous bladder tumor history. 


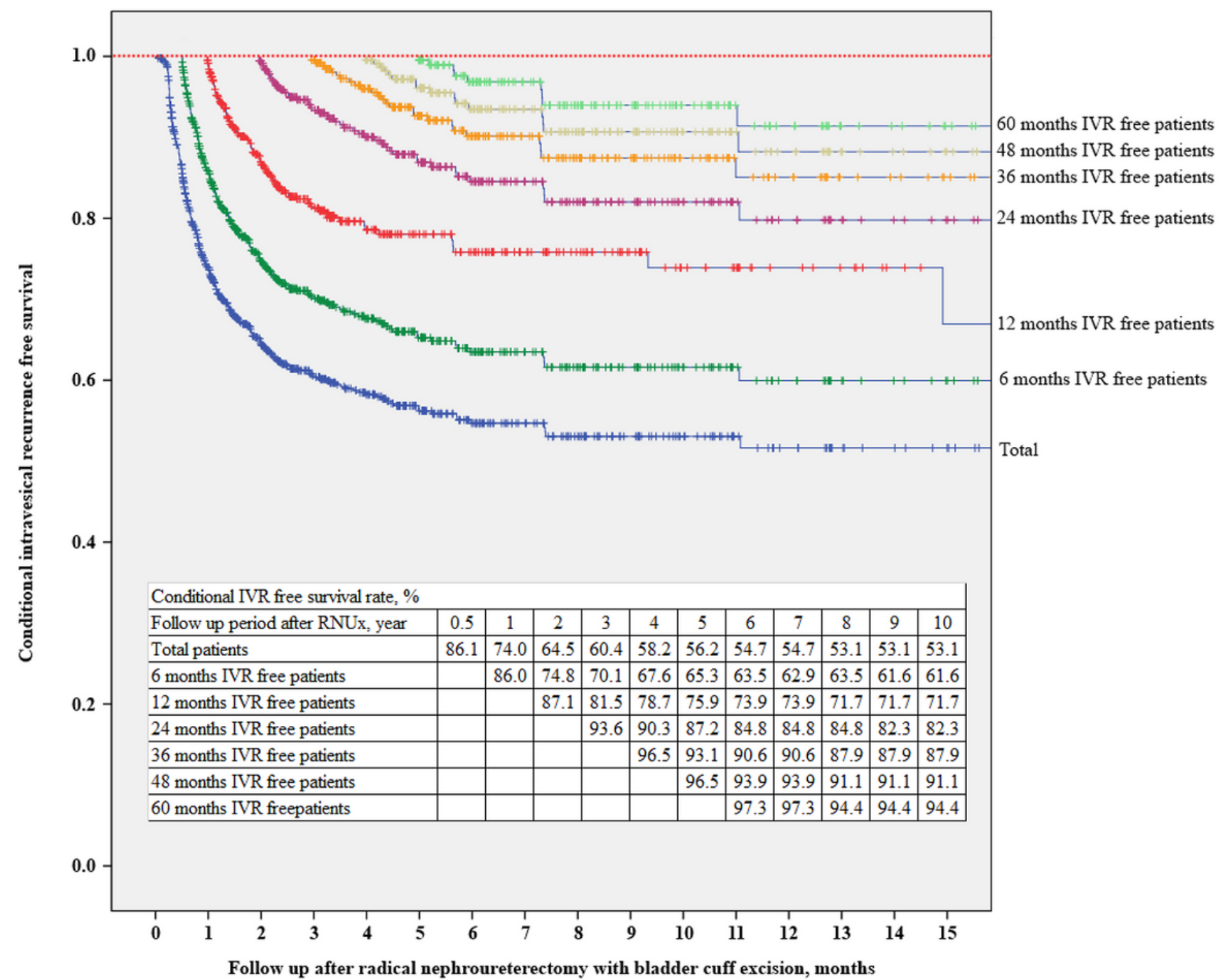

Figure 3

Conditional intravesical recurrence free survival. IVR = intravesical recurrence; RNUx = radical nephroureterectomy with bladder cuff excision. 